\title{
High School-University Cooperation in the Gifu Prefecture, Japan by CanSat and Space Engineering Remote Course
}

\author{
Minoru Sasaki ${ }^{1, *}$, Makoto Asahara ${ }^{1}$, Takeshi Miyasaka ${ }^{1}$, Hiroshi Sudou ${ }^{1}$, Tetsuya \\ Mouri $^{1}$, Satoshi Nishida ${ }^{1}$, Shuhei Takahashi ${ }^{1}$, Yoshinari Kobayashi ${ }^{1}$, Jun Nakaya ${ }^{2}$, \\ Tomohiro Kakumu ${ }^{3}$
}

${ }^{1}$ Faculty of Engineering, Gifu University
${ }^{2}$ National Institute of Technology, Gifu College
${ }^{3}$ Gifu International Takumi Academy
${ }^{*}$ Corresponding author. Email: sasaki@gifu-u.ac.jp

\begin{abstract}
Since 2016, Gifu University, the Gifu Prefecture, the Gifu Prefectural Board of Education, the Gifu Kakamigahara Aerospace Museum, and the National Institute of Technology, Gifu College have been part of the Regional Revitalization Promotion Project by the Center of Community (and Intelligence) University (COC + ) program of Gifu University's Regional Cooperation Center. This program has given high school students from the Gifu prefecture the opportunity to experience the education and research of Gifu University in a high school-university collaboration project using the video conference system provided by the Ministry of Education, Culture, Sports, Science and Technology. The project conveys the charm of the aerospace industry in the Gifu prefecture to foster and arouse motivation to work in the industry, provide basic knowledge about space engineering, and play an active part in the future artificial satellite, rocket, aviation industry. We thus held a space engineering course for the purpose of developing human resources.
\end{abstract}

Keywords: High School-University Cooperation, CanSat, Space Engineering Remote Course, Industrygovernment-academia collaboration, COC+ program.

\section{INTRODUCTION}

In 2016, Gifu University, the Gifu Prefecture, and Kakamigahara City started the Space Engineering Course as a high school-university collaborative project using the video conferencing system of the COC and COC + programs of the Regional Cooperation Center of Gifu University. Currently, the aerospace industry in the Gifu Prefecture boasts a high concentration rate, with the number of establishments and employees ranking second in the country and the value of manufactured goods shipped ranking third in the country. In addition, the Gifu Prefecture has positioned the aerospace industry as a growth field to be prioritized in the Gifu Prefecture Growth and Employment Strategy formulated in March 2014 with the aim of developing the prefecture's economy and expanding employment. Under these circumstances, there is an extremely high demand for human resources education in the aerospace industry to develop and secure excellent human resources and leaders in the industry. With a sense of crisis in this regard, we provided students attending high schools in the Gifu Prefecture with an opportunity to experience cutting-edge education and research at Gifu University to display the appeal of the aerospace industry for the next generation. The course aims to help cultivate and arouse motivation to work in the industry, provide students with basic knowledge about space engineering, and develop human resources who will play an active role in the artificial satellite, rocket, and aviation industries in the future. We decided to start such a course because of the results of our previous research [1-4]. Thanks to the cooperation of related organizations, there were 36 graduates from nine schools (including two female 
students) in 2016, and in 2017, there were 16 schools and 34 students (including seven female students). 2018 saw 13 schools with 42 students (including six female students), and 2019 had 18 schools with 55 students (including 10 female students). Finally, 2020 had 10 schools with 44 students (including 27 female students), as shown in Figure 3. Thanks to the cooperation of related organizations, there were 211 graduates from 66 schools from 2016 to 2021.

The unique feature of this course is that students who are spread all over the prefecture can take lectures at their affiliation using the video conferencing system, as well as visit the Japan Aerospace Exploration Agency (JAXA) and the National Astronomical Observatory. With the cooperation of related organizations, we can provide cutting-edge space education.

\section{COURSE IMPLEMENTATION OUTLINE}

1) Implementation period:

Every year from June to December.

Number of classes (excluding opening and closing ceremonies): nine in total (two times/month).

2nd and 4th Wednesdays from 16:00 to 17:00 (1 hour) (in principle).

2) How to attend:

In addition to taking lectures at the school to which they belong, students also receive tours of the Japan Aerospace Exploration Agency (JAXA), etc. using a TV conference system that uses the Internet.

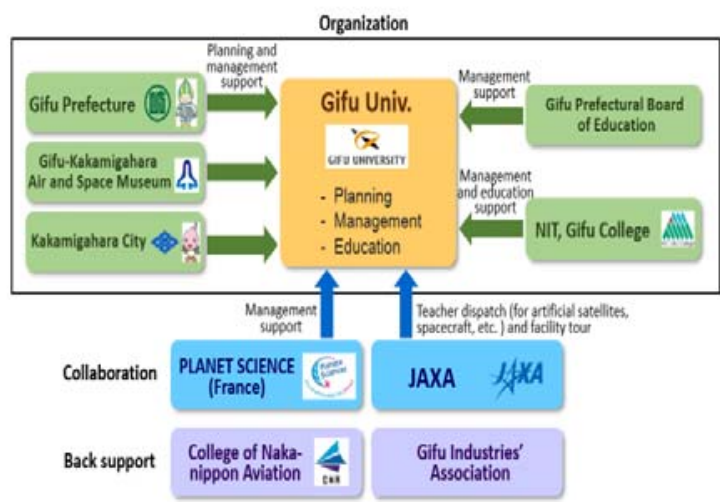

Figure 1 Organization of the Space Engineering Course.

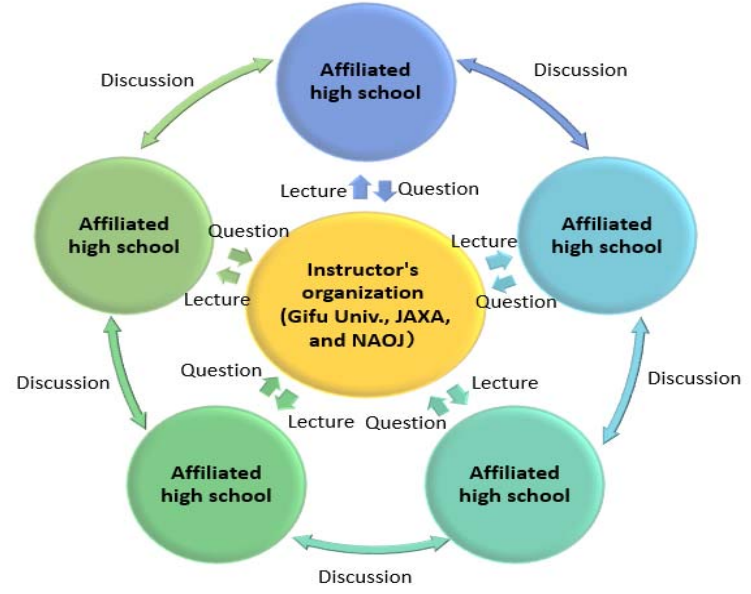

Figure 2 TV conference system.

3) Eligibility for participation:

Students enrolled in high school in the Gifu prefecture and students up to the third grade of the National Institute of Technology, Gifu College.

4) Recruitment personnel: about 50 people.

5) Completion requirements: At least $2 / 3$ of the course and report submission (video can be taken at a later date if convenient).

6) Lecturer: Gifu University faculty member, JAXA, and other related organizations.

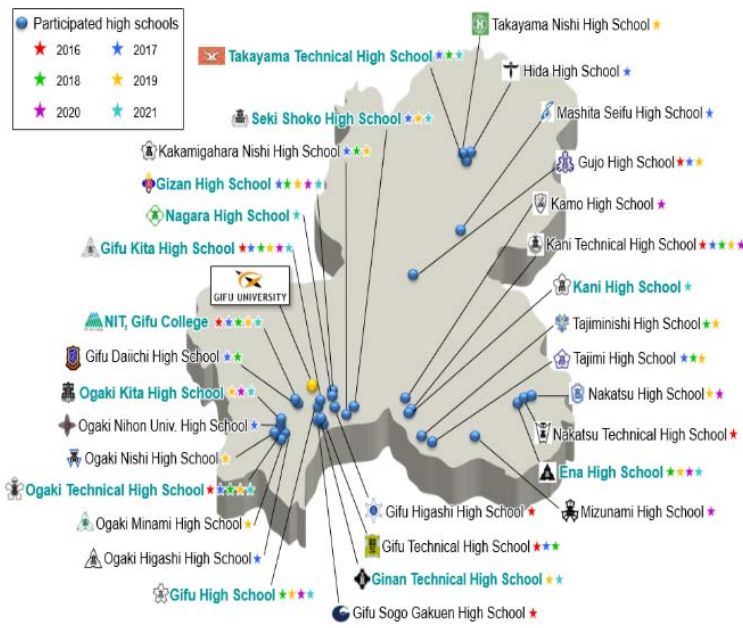

Figure 3 Distribution of participating high schools.

7) Main event:

Gifu University (Implementing entity: Gifu University Regional Collaboration Center).

8) Joint event: 
The Gifu Prefecture, Kakamigahara City, the Gifu Prefectural Board of Education, and the National Institute of Technology, Gifu College.

9) Support:

College of Naka-Nippon Aviation and Gifu Prefectural Industrial Association.

10) Cooperation:

Japan Aerospace Exploration Agency (JAXA) and Planète Sciences (France).

\section{CONTENTS OF THE CLASS AND 2017 TOUR EXAMPLE}

\subsection{TOUR}

On the first day, we conducted a facility tour of the National Astronomical Observatory of Japan, and after receiving a lecture on the outline of the National Astronomical Observatory of Japan from Professor Goda of the JASMINE Study Office, we visited the tour course of the National Astronomical Observatory of Japan. Students can see historical buildings such as the wooden telescope dome built in the Taisho era and the Einstein Tower that challenged the proof of general relativity, as well as the prototype of the infrared small astronomical satellite nano-JASMINE. In addition, students get oriented to the Advanced Technology Center for Equipment Development and receive detailed explanations of the state-of-the-art development site from Professor Noguchi, the director of the center, and other experts in astronomical equipment development.

On the second day, we conducted a facility tour at the JAXA Tsukuba Space Center, and after arriving, the students were impressed by the rocket displayed in front of them. After that, we participated in a bus tour inside JAXA and were able to tour the astronaut training facility and the control room that actually communicates with the space station. We also visited the space dome where models of artificial satellites and space stations are exhibited, with explanations by Mr. Daisaku Ozawa of the JAXA Kibo Utilization Center.

\subsection{CLASS CONTENTS}

\section{(1) [Satellite Orbits] by Prof. Jun Nakaya}

Artificial satellites flying in outer space are mainly affected by universal gravitation from the sun and planets. In this lecture, after explaining the mechanism of artificial satellites, the professor explains the principle of space flight and the types of orbits. Students also perform simple orbit calculations using knowledge of high school mathematics and high school physics.

(2) [How to Launch a Rocket and CanSat up to 2000m in France] by Prof. Minoru Sasaki
This class is part of the Experimental Rocket Launching Campaign project sponsored by Planète Sciences, which belongs to the French National Space Research Center (CNES). Gifu University graduate school rocket team has participated in CNES student rocket launching competition since 2005. By completing a series of processes of experimentation, measurement planning, design, production, launch, result analysis, and reporting through the development of experimental rockets and CanSats, a wealth of education and solid specialized knowledge are gained. The purpose is to train advanced and global professionals in autonomy and internationality in addition to skills, broad perspective, comprehensive judgment, and excellent communication skills.

(3) [Orbital Experiment (Micro-gravity Combustion Experiment)] by Prof. Shuhei Takahashi

At the International Space Station (ISS), scientific experiments in various fields are being conducted in a micro-gravity environment with almost no gravity. Japan has a history of being the first country to use the microgravity environment in the field of combustion research, and many advanced studies are still being conducted. In the lecture, we introduce the space fire experiment (FLARE project) using the Solid Combustion Experiment Module (SCEM) launched on the ISS at "Kounotori 9," conducted by the research team of Gifu University.

(4) [Artificial Satellite Control Engine] by Prof. Takeshi Miyasaka

Artificial satellites are constantly out of orbit due to atmospheric resistance and the gravitational pull of the moon. Therefore, a small rocket must be injected to put the satellites back in place. In this class, the professor explains the performance required of rockets for this work and introduce the electric rocket that is expected to be used not only for artificial satellites but also for spacecraft, etc. together with the mission.

(5) [Measurement and Signal Processing] by Prof. Tetsuya Mouri

Artificial satellites and space stations measure a lot of natural environment data such as weather information. In this course, the professor introduces simple measuring equipment that can also be used in CanSat and explain how to process the measured data.

(6) [Artificial Satellite Power System] by Prof. Satoshi Nishida

Electricity used by artificial satellites is generated using solar cells. In the class, the professor provides general information such as what solar cells are, the characteristics of solar cells used in artificial satellites, and how they differ from solar cells on the ground. 
(7) [Viewing the Universe with an Earth-sized Telescope-Black Holes Explored with Modern Space Technology-] by Prof. Hiroshi Sudou

In order to pursue the truth of the universe, it is necessary to observe celestial bodies with electromagnetic waves of various wavelengths. In this course, students learn about the development of space observation technology such as telescopes and artificial satellites, mainly using observational research on black holes as an example. In addition, we discuss the future of space engineering and space science.

(8) and (9) have external lecturers.

\section{CANSAT KOSHIEN 2017 GIFU REGIONAL COMPETITION}

The purpose is to launch a CanSat (a simulated artificial satellite of the size of a 350-ml empty can) made by a high school student and compete for technical ability and creativity through the process of release, descent, and landing in the sky. Additional reasons are

(1) To make people feel the fun and charm of science and engineering and to raise their interest in these disciplines.

(2) To experience the work of building a satellite and implement the knowledge learned in the classroom.

(3) To provide students with not only the given tasks but also the ability to discover the tasks themselves and improve their presentation ability.

(4) To support the choice of courses in science and engineering.

(5) The teams participating in the national tournament will be selected.

\subsection{Examination Contents}

The four examinations under considerations are the pre-presentation examination, aircraft examination, performance examination, and post-presentation examination. The school to participate in the national competition is decided based on the performance in the examinations. In addition to examining the performance of the CanSat at the time of qualifying, the future potential (improvement plan for the national competition and its management plan) will be considered.

\section{(1) Pre-presentation examination}

Give a presentation within 5 minutes. Explain the mission idea "How to set a mission by yourself and realize it." We will also explain not only the mechanism and performance of the CanSat, but also the carrier release mechanism. In the pre-presentation, the originality and technology of the CanSat and release mechanism will be examined. The format of the presentation material is free.

(2) Aircraft examination

The regulation of CanSat is based on the 2018 CanSat Koshien National Convention Implementation Guidelines. Measure size, weight, etc.

(3) Performance examination

Put the self-made CanSat in the mounting case provided by the operating entity, mount it on the model rocket and drop it, release the CanSat from the mounting case, execute the mission set by yourself, and check the mission result after dropping. The drop altitude of the CanSat is planned to be around $50 \mathrm{~m}$.

- Confirm that the released CanSat is stably lowered.

- When landing, check if the body of the CanSat is damaged.

- Confirm whether the mission set in the prepresentation has been achieved.

(4) Post-presentation examination

Self-evaluate the results of the missions you set yourself and announce the improvement plan and management plan (schedule, etc.) for the national convention. The format of the presentation material is free.

- Examination time: 10 minutes (7 minutes for presentation, 3 minutes for Q \& A).

(5) Overall evaluation criteria

- Is it possible to incorporate, implement, and achieve new ideas?

- Is the mission highly original, not the conventional method?

- How surely was the idea realized and achieved, even if it was the same as before?

- Is it possible to set and carry out a highly meaningful mission?

- When acquiring data in a mission, was it possible to combine multiple data for complex analysis? (For example, the physical condition can be reproduced properly by combining the acceleration and the data of the illuminometer and the thermometer).

- Did you carry out in-depth verification of the consistency of the information obtained in the mission?

And so on. 


\section{QUESTIONNAIRE RESULTS FROM 2017 TO 2020 AT THE CLOSING CEREMONY}

Date: From 2016 to 2020 Venue: Gifu University Questionnaire responses: 233.

(1) Please tell us about your satisfaction with the closing ceremony of the Astronautics Course.

Very satisfied: 97, Satisfied: 90, Normal: 11, Dissatisfied: 3, Very dissatisfied: 1.

(2) Please tell us your impressions of the closing ceremony of the space engineering course (multiple answers).

1. I was interested in the content of the lecture: 182.

2. I wanted to take a space engineering course: 19 (not including current students).

3. I felt that space education in the Gifu Prefecture should be further promoted: 96 .

4. I wanted to do space-related work in the future: 50.

5. It was fun to be able to visit the laboratory: 37 .

6. It was fun to be able to tour the radio telescope: 22.

7. I deepened my understanding of the space mission by watching the exhibition: 20 .

8. I enjoyed watching the rocket launch demonstration: 10.

9. Others/No answer: 4.

(3) < Free description>

- I was interested in the rich content of the space engineering course.

- It was really nice to be able to participate.

- I wanted you to teach me not only about space but also about aircraft. (Details)

- I was interested in aerospace and would like to make use of it in future career choices.

- I learned a lot.

- I thought it was important to decide on employment based on the political situation.

- There was so much I could learn through the course. During the closing ceremony, I looked back on my life so far.

- I am glad that I had a lot of valuable experiences. In particular, Professor Akiyama's lecture and rocket launch demonstration were unique experiences. I should have had a break if possible.
- Thank you for your kind lectures. It was a valuable learning opportunity for the students. I look forward to future efforts and growth.

- It was an interesting lecture.

- It was difficult for CanSat to fail to acquire data. The lecture left a strong impression on me.

\section{CONCLUSIONS}

The Chubu region is Asia's No. 1 aerospace industry cluster formation special zone, and the Gifu Prefecture has many companies involved in aerospace. Therefore, there is a high awareness of aerospace science in the region. Therefore, research and educational institutions such as universities are provided with opportunities for aerospace education with enhanced specialization for elementary and junior high school students who have become more interested in aerospace science to make them human resources who contribute to the aerospace industry. It is thus required to establish a training system. Therefore, centering on Gifu University, which is the supervising institution to which the authors belong, provides an education resource for high school students, technical college students, university students, and graduate students at various bases including joint participation institutions and research cooperation institutions. Each institution has organized many events related to aerospace science and has contributed to the development of young aerospace personnel and the revitalization of the aerospace industry. The educational effect on students is clear from the results of questionnaires, etc., and it is expected that more practical manufacturing courses will be opened. Some courses have been realized and have been effective, but manufacturing and running costs are high for these courses, and it is difficult to secure financial resources, so that presents a future issue.

\section{ACKNOWLEDGMENTS}

Instrumental institutions for holding this course include the Gifu Prefecture, Kakamigahara City, the National Institute of Technology, Gifu College, the Gifu Prefectural Board of Education, the College of NakaNippon Aviation, the Gifu Prefectural Industrial Association, the Japan Aerospace Exploration Agency, and Planète Sciences (France), as shown in Figure 1. We would like to express our gratitude once again for the cooperation of all concerned parties and places.

\section{REFERENCES}

[1] R. Tsubouchi, K. Nakahira, K. Shimomura, S. Ueda, N. Hirasha, T. Takada, Development, course design and practice of mission planning type CanSat for student group education, Engineering Education, 2018, vol. 66, no. 2, pp. 79-84. 
[2] T. Takada, M. Wakabayashi, K. Murakami, K. Imai, A. Masuoka, S. Ueda, Results of the interlocking "CanSat Course / CanSat Tournament" for space human resources education, Engineering Education, 2017, vol. 65 no. 2, pp. 26-30.

[3] N. Ogushi, M. Sasaki, S. Ito, N. Nakano, A. Asai, N. Ozeki, N. Ikenobe, M. Lee, Research on the development of small experimental rockets and autonomous mobile simulation satellites, Journal of the AEM Society of Japan, 2009, vol. 17, no. 2, pp. 360-366.

[4] M. Sasaki, N. Nakano, S. Ohmayu, N. Ogushi, System development of an experimental rocket for launching campaign organized by French association Planete Sciences, France, Trans. JSASS Space Tech Japan, 2009, vol. 7, No. 26, pp. 13-18. 